\title{
Assessment of spatial uncertainty of heavy rainfall at catchment scale using a dense gauge network
}

\author{
Sungmin $\mathbf{O}^{1,2, a}$ and Ulrich Foelsche $\mathbf{e}^{1,2,3}$ \\ ${ }^{1}$ Institute for Geophysics, Astrophysics, and Meteorology/Institute of Physics (IGAM/IP), \\ NAWI Graz, University of Graz, Graz, Austria \\ ${ }^{2}$ FWF-DK Climate Change, University of Graz, Austria \\ ${ }^{3}$ Wegener Center for Climate and Global Change (WEGC), University of Graz, Graz, Austria \\ anow at: Biogeochemical Integration, Max Planck Institute for Biogeochemistry, Jena, Germany
}

Correspondence: Sungmin O (sungmin.o@uni-graz.at)

Received: 3 October 2018 - Discussion started: 11 October 2018

Revised: 13 June 2019 - Accepted: 4 June 2019 - Published: 8 July 2019

\begin{abstract}
Hydrology and remote-sensing communities have made use of dense rain-gauge networks for studying rainfall uncertainty and variability. However, in most regions, these dense networks are only available at small spatial scales (e.g., within remote-sensing subpixel areas) and over short periods of time. Just a few studies have applied a similar approach, i.e., employing dense gauge networks to catchmentscale areas, which limits the verification of their results in other regions. Using 10-year rainfall measurements from a network of 150 rain gauges, WegenerNet (WEGN), we assess the spatial uncertainty in observed heavy rainfall events. The WEGN network is located in southeastern Austria over an area of $20 \mathrm{~km} \times 15 \mathrm{~km}$ with moderate orography. First, the spatial variability in rainfall in the region was characterized using a correlogram at daily and sub-daily scales. Differences in the spatial structure of rainfall events between warm and cold seasons are apparent, and we selected heavy rainfall events, the upper $10 \%$ of wettest days during the warm season, for further analyses because of their high potential for causing hazards. Secondly, we investigated the uncertainty in estimating mean areal rainfall arising from a limited gauge density. The average number of gauges required to obtain areal rainfall with errors less than a certain threshold $(\leq 20 \%$ normalized root-mean-square error - RMSE - is considered here) tends to increase, roughly following a power law as the timescale decreases, while the errors can be significantly reduced by establishing regularly distributed gauges. Lastly, the impact of spatial aggregation on extreme rainfall was examined, using gridded rainfall data with various horizontal
\end{abstract}

grid spacings. The spatial-scale dependence was clearly observed at high intensity thresholds and high temporal resolutions; e.g., the $5 \mathrm{~min}$ extreme intensity increases by $44 \%$ for the 99.9 th and by $25 \%$ for the 99th percentile, with increasing horizontal resolution from 0.1 to $0.01^{\circ}$. Quantitative uncertainty information from this study can guide both data users and producers to estimate uncertainty in their own observational datasets, consequently leading to the sensible use of the data in relevant applications. Our findings could be transferred to midlatitude regions with moderate topography, but only to a limited extent, given that regional factors that can affect rainfall type and process are not explicitly considered in the study.

\section{Introduction}

Rainfall data are one of the most important inputs for hydrological as well as climatological studies and applications. Furthermore, fit-for-purpose information derived from rainfall data is crucial for a wider range of users, such as civil engineers, water resource managers, and governments. To meet the needs of diverse user groups, rainfall observational datasets from in situ measurement and remote sensing have been greatly enhanced in terms of both data quality and resolution (e.g., Berezowski et al., 2016; Hou et al., 2014; Keller et al., 2015; Yatagai et al., 2012). Often, rainfall data are required as areal estimates at the scale of interest, for instance, at grid or catchment scales. Point measurements from in situ 
gauge observations are spatially aggregated or interpolated to estimate the areal distribution of rainfall, and hence the accuracy of areal rainfall data is highly dependent on spatiotemporal variability in rainfall events and density of observation points (Girons Lopez et al., 2015; Hofstra et al., 2010; Villarini et al., 2008; Wood et al., 2000). This limits the understanding of fine-scale rainfall processes, particularly of extreme events (Sillmann et al., 2017). Gridded rainfall data are also available from remotely sensed observations at high spatial resolutions (e.g., $1-5 \mathrm{~km}^{2}$ for radar data or $0.1^{\circ} \times 0.1^{\circ}$ for satellite data). While those datasets are good alternatives to address a number of the issues relating to the scarcity of gauges, rainfall variability at subpixel scales can still not be fully resolved (Peleg et al., 2013; Tokay et al., 2014). Moreover, systematic errors can be large (Svensson and Jones, 2010), and the quality of remotely sensed data therefore strongly relies on gauge-based data that are used for their regional validation and correction (Kann et al., 2015; O et al., 2018b; Steiner et al., 1999).

Addressing the issue of spatial variability in and uncertainty of rainfall has been tackled over many years with various purposes. For instance, evaluation of satellite or radarrainfall products involves investigation of larger-scale rainfall processes to assess the ability of remote sensing in capturing the inter-pixel rainfall variability (e.g., Chaudhary et al., 2017; Dhib et al., 2017; Lockhoff et al., 2014). On the other hand, small-scale rainfall processes are of interest in identifying the effect of intra-pixel variability in rainfall on the performance of remote sensing (e.g., Ciach and Krajewski, 1999, 2006; Gebremichael and Krajewski, 2004; Habib and Krajewski, 2002; Peleg et al., 2013; Tan et al., 2018; Tokay et al., 2014). To quantify the rainfall uncertainty, observational data from highly dense rain-gauge networks have been employed as a ground truth. Peleg et al. (2013) used multiple rain gauges within a radar subpixel area $\left(4 \mathrm{~km}^{2}\right)$ and examined the contribution of gauge sampling error to the total radar-rainfall estimation error. Using relatively long-term gauge data (5 years), Tokay et al. (2014) analyzed the spatial correlation of rainfall for different seasons and weather systems within the footprint size of microwave satellite sensors.

A similar approach employing dense gauge networks can be adopted to diagnose the spatial variability in and uncertainty of rainfall at catchment scales (e.g., $100-500 \mathrm{~km}^{2}$ ). Such scales are of great interest not only for the evaluation of remotely sensed data but also for hydrological applications like runoff modeling or gauge network design. Wood et al. (2000) examined the accuracy of areal estimates of rainfall over a $135 \mathrm{~km}^{2}$ basin according to the HYdrological Radar EXperiment network consisting of 49 rain gauges. The network later provided a 6-year rainfall dataset (from 50 gauges) for the study of Villarini et al. (2008), where a comprehensive analysis of temporal and spatial sampling uncertainties was conducted. However, most of the local areas do not have adequately dense gauge networks, which limits the comparison and verification of findings from the aforementioned stud- ies across diverse rainfall regimes. Schroeer et al. (2018) recently employed the WegenerNet (WEGN) Feldbach region and the surrounding operational rain-gauge stations to sample summertime convective extreme events at sub-hourly to hourly scales and found a power-law decay of the event maximum area rainfall with increasing interstation distance (1 to $35 \mathrm{~km})$.

In this paper, in order to contribute to the effort for better and broader assessment of the rainfall spatial variability and associated uncertainty, we employed 10-year rainfall data from the WEGN, a high-density network in southeastern Austria (Kirchengast et al., 2014). The network includes 150 rain gauges deployed over an area of $\simeq 300 \mathrm{~km}^{2}$, approximately corresponding to one gauge per $2 \mathrm{~km}^{2}$. First, following previous studies (e.g., Villarini et al., 2008; Peleg et al., 2013; Tokay et al., 2014), we quantified the spatial variability in rainfall utilizing a corrologam between the gauges to understand the spatial characteristics of rainfall in the region.

Second, we investigated the uncertainty in estimating areal rainfall caused by a limited number of point observations. Given that the properties of individual rainfall events can be different from all-event averages (Ciach and Krajewski, 2006; Eggert et al., 2015), we focused on events with a potentially high impact, which we defined as the top $10 \%$ wettest days during the warm season (May-September). The accuracy of areal rainfall estimation is a long-standing issue, e.g., in catchment modeling because error and uncertainty in rainfall data can propagate into large variations in simulated runoff, and thus it has been dealt with in diverse manners. For instance, the influence of spatial representations of rainfall input to runoff errors has been demonstrated through modeling studies (e.g., Bárdossy and Das, 2008; Xu et al., 2013). The error in catchment-scale areal mean rainfall has also been directly quantified by employing high-resolution gauge data (e.g., Villarini et al., 2008; Wood et al., 2000; Ly et al., 2011). We followed the latter approach using the WEGN rainfall data.

Finally, we compared extreme rainfall at different spatial and temporal scales using gridded rainfall fields to quantitatively assess the impact of spatial averaging on the definition of extremes. The identification of rainfall extremes based on intensity thresholds is common practice; however, the considered spatial scale of rainfall data defines different sets of extreme events (Eggert et al., 2015), potentially affecting threshold-based early warning systems (Marra et al., 2017). Although gridded datasets have been used in a range of applications like assessments of climate change impacts or evaluation of climate models, a common caveat of using the datasets in the study of extreme rainfall is that the quality of gridded rainfall data is highly constrained by the location and density of input weather station data (Hofstra et al., 2010; Prein and Gobiet, 2017). By contrast, the quasi-regular configuration of WEGN on an approximately $1.4 \mathrm{~km} \times 1.4 \mathrm{~km}$ grid permits robust examination of the frequency and intensity of rainfall extremes at various horizontal resolutions. 
Consequently, this study aims to assess spatial uncertainty of rainfall at the catchment scale using rain-gauge data, with a focus on heavy and extreme rainfall events. This paper is structured as follows. Section 2 describes WEGN rain-gauge data and regional rainfall climatology. Sections 3, 4, and 5 present results and discussion of the data analysis. We close with a summary and conclusions in Sect. 6.

\section{WEGN rainfall data and regional rainfall climatology}

The 10-year rainfall data (2007-2016) are obtained from the WEGN Feldbach region network in southeastern Austria (Kirchengast et al., 2014). Of 154 weather stations, 150 stations that are equipped with tipping-bucket rain gauges are used in this study (Fig. 1). Raw rain-gauge data are aggregated every $5 \mathrm{~min}$. The rainfall data are quality-controlled by the WEGN data processing system, and furthermore, systematic errors (undercatch) of the rainfall data that are used in this study were comprehensibly analyzed and corrected by $\mathrm{O}$ et al. (2018a). The gauges are almost uniformly spaced over an area of $20 \mathrm{~km} \times 15 \mathrm{~km}$ with moderate topography (about 260 to $520 \mathrm{~m}$ altitude). The inter-gauge distances range from approximately 0.7 to $23.4 \mathrm{~km}$. The gridded fields of rainfall are constructed by an inverse distance weighting (IDW), using the power parameter $p=2$, on a $200 \mathrm{~m} \times 200 \mathrm{~m}$ Universal Transverse Mercator grid. The gridded data are constructed at $5 \mathrm{~min}$ resolution. The sub-daily to daily data used in this study are obtained by accumulating the $5 \mathrm{~min}$ data. WEGN station and gridded data products are available at https://wegenernet.org/portal/ (last access: 3 July 2019).

Southeastern Austria including the Feldbach region is influenced by both continental and Mediterranean climates. The region receives high amounts of rainfall during summer months. The occurrence of thunderstorms and hail is higher than in other parts of Austria (Matulla et al., 2003). Figure 2 shows average diurnal variations of rainfall and temperature over the entire network during the study period. The WEGN area is characterized by warm and wet months from May through September (hereafter "warm season") and relatively cold months without much rainfall during the remaining 7 months (hereafter "cold season"). The average monthly rainfall is $102.8 \mathrm{~mm}$ in the warm season, while it is $48.9 \mathrm{~mm}$ in the cold season. The diurnal signal is more clearly seen in the warm season for both rainfall and temperature. Rainfall maxima occur often in the early afternoon through midnight, shortly after maximum temperature, implying that a major contribution to the warm season rainfall is from shortduration convective events. Because diurnal heating plays an important role in triggering thermal convection, most inland regions show afternoon rainfall maxima (Dai et al., 2007). Extreme daily precipitation, however, can also be caused by Genoa lows (Hofstätter and Blöschl, 2019), which transport
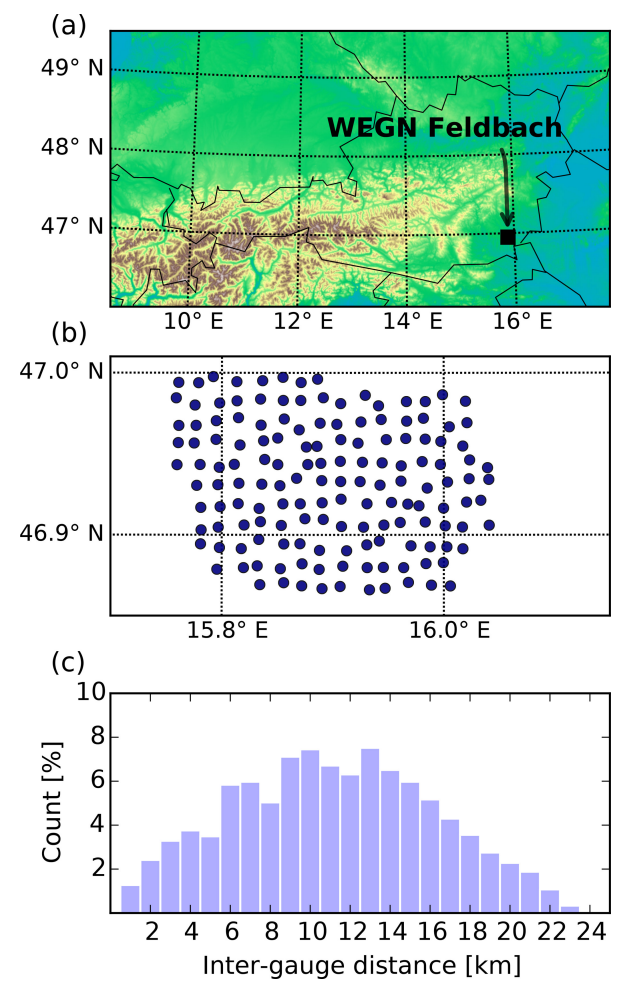

Figure 1. (a) WegenerNet Feldbach region (WEGN) network in southeastern Austria, (b) location of 150 tipping-bucket rain gauges, and (c) inter-gauge distances, rounded to the nearest $1 \mathrm{~km}$ bins. The map is created using the Matplotlib basemap toolkit (Hunter, 2007).

humidity from the Mediterranean Sea, yielding intense rainfall with a long duration.

\section{Spatial variability in rainfall}

The spatial structure of rainfall events is studied using Pearson's correlation coefficient between all pairs of rain gauges. Pearson's $r$ is the most commonly used rainfall correlation estimator (e.g., Ciach and Krajewski, 2006; Jaffrain and Berne, 2012; Peleg et al., 2013; Tokay et al., 2014; Villarini et al., 2008). At sub-daily and daily timescales from $5 \mathrm{~min}$ to $24 \mathrm{~h}$ (06:00-06:00 UTC), the correlation of rainfall among rain gauges is calculated for each year. A 1-year period includes a set of the warm season (May to September) and cold season (October to next April). The incomplete years (i.e., first and last years) are excluded from the calculation of all months (May to next April), whereas the warm and cold seasons have 10 annual curves each. The data pairs when both record zero rainfall are discarded. The correlation values in each period were then sorted according to the separation distance of gauge pairs and averaged into the nearest $1 \mathrm{~km}$ distance bins. We fitted a three-parameter exponential function to the average correlations. The distance bins for fitting the model were taken up to and including $15 \mathrm{~km}$ given the net- 

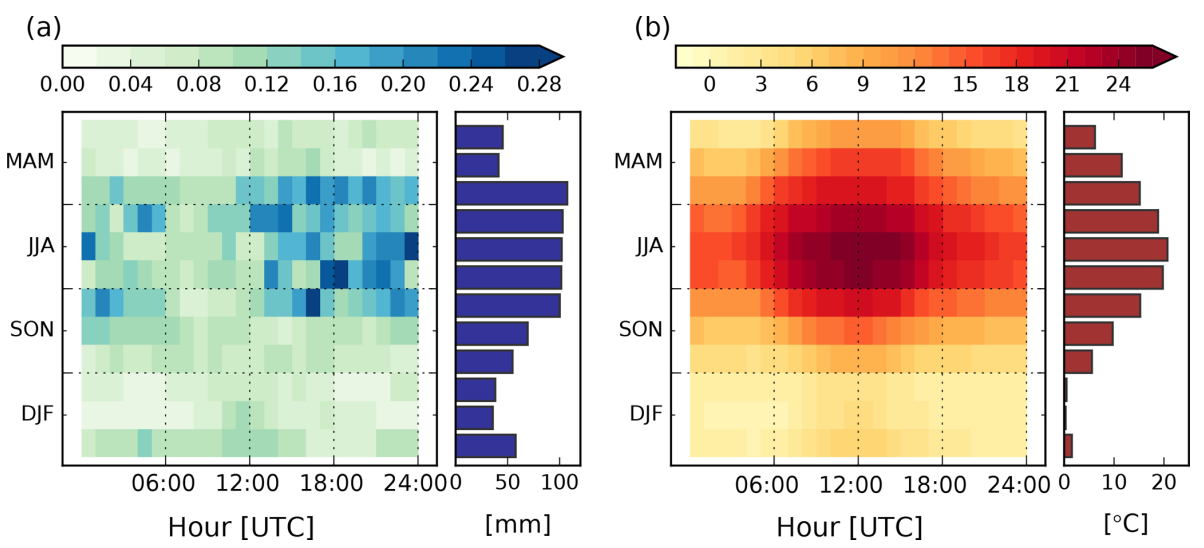

Figure 2. Diurnal cycles of (a) rainfall and (b) temperature derived from WEGN observational data.

work dimension, which means that rainfall data pairs were sampled uniformly for any spatial direction. The spatial correlation $(r)$ at separation distance $h$ is

$r(h)=c_{1} \exp \left[-\left(\frac{h}{c_{2}}\right)^{c 3}\right]$,

where $c_{1}$ represents the nugget effect, $c_{2}$ is the correlation distance, and $c_{3}$ is the shape factor. The parameters are determined by least-squares curve fitting. Figure 3 shows the spatial correlation of all months and warm and cold seasons for four selected accumulation times. A logarithmic transformation is applied to the data, $\log (x+1)$, to keep zero rainfall, where $x$ is in rainfall (in $\mathrm{mm}$ ). As the transformation makes rainfall data conform more closely to the normal distribution, the effects of extreme values on correlation coefficients are mitigated (Habib et al., 2001; Jaffrain and Berne, 2012). This results in slightly lower correlations (not shown); however, the overall pattern of correlation decay curves remains unaffected. The data after the $\log$ transformation are used in the figure.

Many factors are known to affect the spatial correlation structure in rainfall. For instance, Habib et al. (2001) examined the sensitivity of correlation estimation in rainfall to the sample size or extreme rainfall events, and Huff and Shipp (1969) demonstrated how the rate of correlation decay varied with different rainfall types. In fact, individual weather systems can exhibit varied spatial characteristics (Habib and Krajewski, 2002; Ciach and Krajewski, 2006; Tokay et al., 2014). In southeastern Austria, including the WEGN area, Schroeer et al. (2018) found much steeper decay in a correlogram function when only extreme summertime convective events are accounted for. We therefore do not make a direct comparison of correlation values with those from other studies, yet we still observe that the behaviors of the correlation decay found in this study are in broad agreement with spatial rainfall correlation structures reported in the aforementioned studies. First, longer accumulation times show higher $c_{1}$ (i.e., smaller microscale variations) and longer cor- relation distance values. Second, short-range correlation decreases rapidly with increasing separation distance, particularly at sub-hourly scales.

The warm season shows higher spatial variability in rainfall compared to the cold season, due to a higher proportion of convective events. The correlation curves of all months show a more similar pattern with the warm season, as expected, given that most of the rainfall events are concentrated during the warm season (see Sect. 2). Tokay et al. (2014) found substantial year-to-year variations especially during autumn and spring. Similarly, WEGN rainfall shows marked interannual variability also during the warm season. It should be noted that the correlation functions of the cold season start with lower $c_{1}$ values than those of the warm season, meaning larger measurement errors and microscale variability in rainfall. This could be related to winter precipitation types in the region. For instance, uncertainty affecting the gauge measurements (e.g., wind-induced bias) may play a bigger role in determining the spatial heterogeneity of neighboring stations during low-intensity precipitation events than during warm season convective events. Another possible reason is that WEGN does not accurately capture solid precipitation (O et al., 2018a), since only few gauges are heated, and thus systematic errors between neighboring gauges can be greater during the cold season, possibly yielding the low $c_{1}$ values.

Figure $4 \mathrm{a}-\mathrm{c}$ summarize the time dependence of the three parameters. Synthesized parameters here are obtained from the fitting function that is constructed by averaging yearly correlation values in each distance bin. Nugget effect values range from 0.71 to 0.98 for the cold season, while they ranged from 0.85 to 0.99 for the warm season. The correlation distance of the cold season at the $3 \mathrm{~h}$ scale nearly corresponds to the correlation distance at the $24 \mathrm{~h}$ scale in the warm season. The parameter values of all months are located between those of warm season and cold season. We found that the dependency of the nugget effect and correlation distance on the timescale is similar to the results by Villarini et al. (2008). The nugget effect parameter changes sharply 


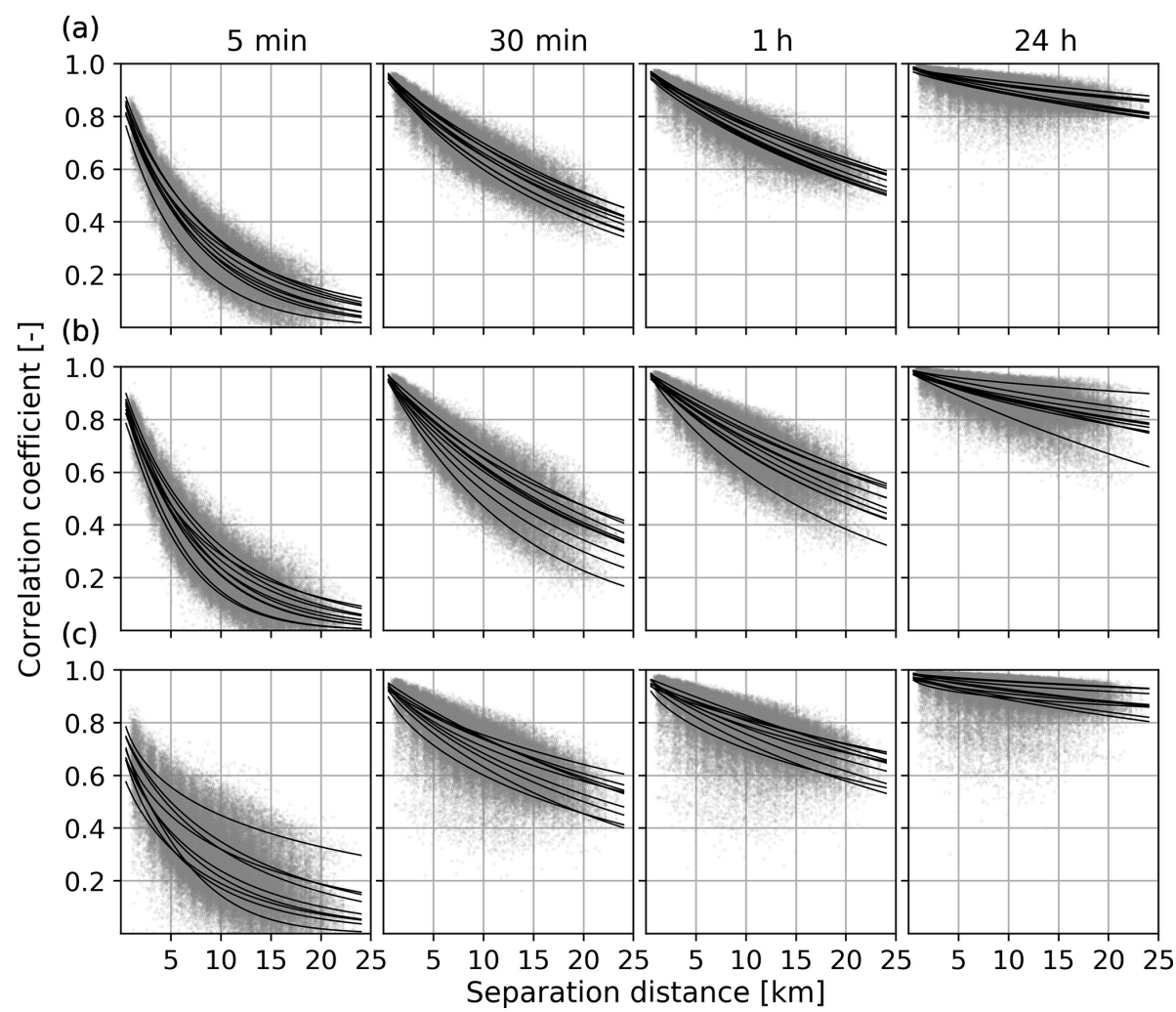

Figure 3. Spatial correlation of rainfall among rain gauges for (a) all months, (b) warm season, and (c) cold season. Four selected accumulation times are shown. Each solid line represents a fitted exponential function for each year up to $23 \mathrm{~km}$ (the longest inter-gauge distance of WEGN). Note that the function is fitted to correlation for separation distances $\leq 15 \mathrm{~km}$ to sample data uniformly for any spatial direction.

at smaller timescales, while the correlation distance appears to be more sensitive for larger timescales. The shape factor of this study, however, does not show a clear increasing or decreasing trend. This is consistent with findings from Peleg et al. (2013) and Tokay et al. (2014). We selected the three-parameter model for the function fitting, because the model shows the minimum root-mean-square error (RMSE) between observed and fitted correlation values across all timescales (Fig. 4d) among the several tested models. Note that we fitted the correlation models to bin-averaged values and thus obtained relatively small fitting errors compared to other studies (e.g., Ciach and Krajewski, 2006, or Tokay et al., 2014). During multiple tests with different fitting models, we found that the fitted correlation distances over $100 \mathrm{~km}$ (e.g., values at accumulation times of $>6 \mathrm{~h}$ in Fig. $4 \mathrm{~b}$ ) are often highly impacted by the selected fitting models. However, this model uncertainty does not affect the general behaviors of the parameters, including their dependence on the timescale and their seasonal differences. Nonetheless, when the spatial scale of observed correlations is limited to a distance of a few kilometers (e.g., $15 \mathrm{~km}$ in our study), the correlation distances estimated from the fitting model should be interpreted with caution. Interested readers may obtain a more detailed discussion of the fitting model in Svoboda et al. (2015).

So far we assume that the correlation structure is isotropic. To check the directionality (anisotropy) of the spatial correlations, we remapped them onto the two-dimensional space (Velasco-Forero et al., 2009; Mandapaka and Qin, 2013). Figure 5 shows the 10-year averaged correlations plotted over $1 \mathrm{~km} \times 1 \mathrm{~km}$ grid cells but only until the e-folding distance (when the correlation drops to around 0.37). While the correlation drops rapidly in all directions over short distances, a strong correlation is observed in an approximate southwest-northeast direction as separation distance increases. The directionality is more pronounced during the cold season, which can be interpreted as a consequence of movement of large-scale weather systems (contrary to summertime convective) along the favored wind direction during the season rather than as an effect of orographic barriers. Such directional characteristics of the correlations are averaged out in Fig. 3. 

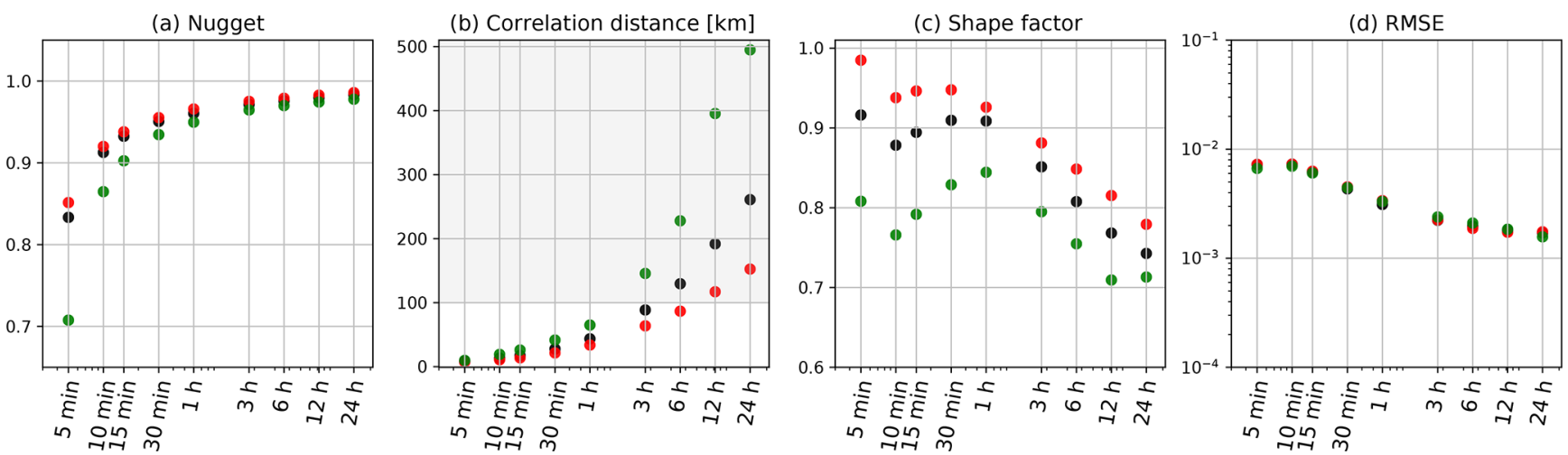

Figure 4. Dependence of (a) nugget effect, (b) correlation distance, and (c) shape factor of the fitted exponential functions on timescale; (d) shows RMSE of fitted correlation values compared to observed values (red: warm season; green: cold season; black: all months). Note that the correlation distance values over $100 \mathrm{~km}$ (shaded in grey) are highly affected by the model selected to estimate the values.
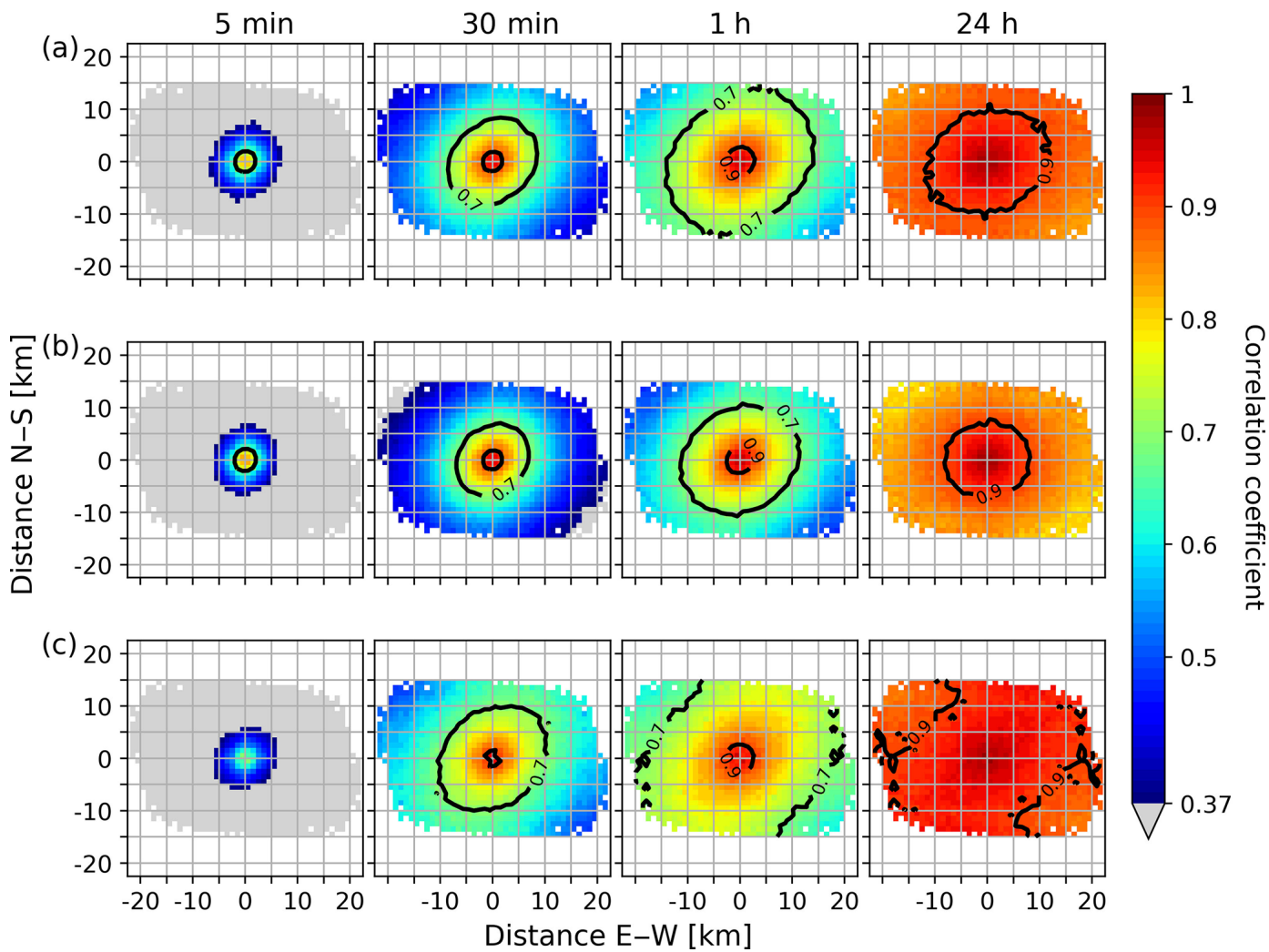

0.5

Figure 5. Same as Fig. 3 but for 10-year averaged spatial correlations in a two-dimensional space which is defined according to the distance between the gauges in east-west direction ( $x$ axis) and north-south direction ( $y$ axis). (a) All months, (b) warm season, and (c) cold season are shown. The values beyond the e-folding distance $(\approx 0.37)$ are colored grey.

\section{Accuracy of areal rainfall estimation during heavy rainfall events}

In this section we investigate data uncertainty associated with areal rainfall estimation. In particular, the study focuses on high-impact rainfall events. While heavy rainfall is one of the major hydrological hazards, its accurate spatial representation over an area remains a subject worthy of inquiry.
Heavy rainfall events are defined as days with total rainfall exceeding the 90th percentile of the daily rainfall without a consideration of rainfall type. Only the warm season is taken into account. As a result, a total of $71 \mathrm{~d}$ are selected. According to our visual inspection of rainfall time series, the selected days likely include mixed rainfall types (short- and long-duration rainfall) rather than a specific type. The me- 
dian of gauge-averaged accumulations is $28.1 \mathrm{~mm} \mathrm{~d}^{-1}$, with a range of 19.8 to $64.1 \mathrm{~mm} \mathrm{~d}^{-1}$ (more information in the Supplement).

We assume that the mean areal rainfall of a full density network represents the "truth". The areal rainfall of $n$-gauge networks ( $n=$ number of gauges) is calculated and compared with the true rainfall to quantify the accuracy of areal rainfall estimation with low-density networks (see also Villarini et al., 2008). Each $n$-gauge network consists of randomly selected 1000 possible gauge combinations. The one-gauge network has 150 cases. As shown in Fig. 6a, the average and spread of normalized RMSEs (NRMSEs) of areal rainfall estimation tend to decrease with a rising gauge number. The mean number of gauges required to obtain areal rainfall with NRMSEs lower than $20 \%$ is given as a function of time resolution in Fig. 6b. The curve (in black) roughly exhibits power-law behavior: $74.2 \times t^{-0.4}$, where $t$ is the time resolution (minute). At the daily scale, more than one gauge per $300 \mathrm{~km}^{2}$ would be sufficient for reaching a $<20 \%$ estimation error. Correspondingly, at the temporal scales of $1 \mathrm{~h}, 30 \mathrm{~min}$, and $5 \mathrm{~min}$, on average more than 12,18 , and 33 gauges, respectively, are needed to achieve the same level of accuracy. Villarini et al. (2008) found that four gauges are necessary at the daily scale for the same accuracy level for an area of $135 \mathrm{~km}^{2}$. Heavy events are not explicitly considered in their study.

One should note that the use of randomly selected gauge combinations only offers a rule of thumb about the required number of gauges to minimize uncertainty in areal rainfall estimates. To demonstrate the role of gauge distribution in determining the estimation error, we selected "good" and "bad" distributions, 100 cases for each, out of the 1000 combinations for each $n$-gauge networks that ranked in the top $10 \%$ and bottom $10 \%$ based on the area of influence (see Supplement). As seen in Fig. 6a (red crosses), the smallest estimation error is obtained with regularly distributed gauges. In other words, a well-designed gauge network allows meeting the desired error limit with a smaller number of gauges (black curve in Fig. 6c). For example, at a $1 \mathrm{~h}$ scale, the $20 \%$ estimation error can be reached using uniformly distributed 8 gauges; however, the same level of accuracy cannot be guaranteed even with 23 rain gauges if their spatial configuration is not properly structured.

We repeated the calculation of the required gauge number to reach the certain accuracy, using sub-areas of 150, 100, and $50 \mathrm{~km}^{2}$, i.e., one-half, one-third, and one-sixth of WEGN area size, respectively (grey lines in Fig. $6 \mathrm{~b}$ and c). For each sub-area, the mean rainfall of all gauges within the area is assumed to be the truth, and the 1000 possible gauge combinations are randomly selected, as we did above. For the $50 \mathrm{~km}^{2}$ area where only 25 gauges are available, all combinations are included when the total possible combinations of $n$ gauges are less than 1000 cases. For any case, the dependence of the accuracy of areal rainfall estimates on the gauge number shows the power-law behavior across timescales. How- ever, the required gauge numbers do not linearly decrease as the considered network area decreases. For smaller areas, we need more number of gauges per square kilometer (i.e., higher gauge density) to reach the same level of accuracy at the same timescale (see inset plots in Fig. 6b and c). Because rainfall variability varies faster within the first few kilometers, more dynamic rainfall variations in the smaller areas cannot be properly captured when the inter-distances of gauges remain the same (i.e., constant gauge density between the sub-areas), particularly for short timescales.

Additionally, the effect of gauge density on event-based rainfall statistics is assessed in Fig. 7. Daily rainfall accumulation and peak hourly rainfall of the 71 heavy daily events are recalculated using predefined sub-networks with gauges ranging from 1 to 16 . The gauges are uniformly spread; the definition of the sub-networks can be found in Supplement. While the sub-network with only one gauge exhibits large overestimation errors for both total and peak rainfall, employing an additional gauge already significantly reduces the degree of errors and yields underestimation error more frequently than overestimation. Given that convective storms occur on scales of a few kilometers, low-density gauges over the region are likely to miss the core of storm. On the contrary, low-density gauges can also overestimate rainfall intensities by capturing only the core of storm, but the magnitude and frequency of these errors appear slightly less than those of the underestimation errors. When more than 10 gauges are available in the area, the impact of gauge number on the spread and mean of errors in area rainfall estimation becomes marginal, as expected from Fig. 6. Note that only two operational meteorological stations exist over the actual WEGN area; the insufficient gauge density may hamper the use of the station data for constructing spatial rainfall information in the region.

\section{Impact of spatial aggregation on extreme rainfall}

We next focus on the uncertainty of area- or grid-averaged rainfall relating to spatial data resolution for the heavy rainfall events. Figure 8 compares rainfall percentiles among the gauges. Grey lines mean a 10th-90th percentile range of rainfall intensities at a given percentile bin. For example, at the 30 min scale, the 99.9th percentile (the top $0.1 \%$ ) rainfall intensity corresponds to roughly $45 \mathrm{~mm} \mathrm{~h}^{-1}$ at most gauges, while it exceeds $52 \mathrm{~mm} \mathrm{~h}^{-1}$ at certain gauges. It is also seen that $10 \%$ of WEGN gauges (i.e., 15 gauges) records are found to be lower than $38 \mathrm{~mm} \mathrm{~h}^{-1}$. The upper tail of the rainfall distribution shows strong spatial variation. Such pointscale extreme rainfall features will be completely missed unless dense rainfall observations exist, or they are inherently smoothed out in gridded data.

In fact, many studies have pointed out that the use of gridded rainfall data can lead to erroneous analyses of smallscale extremes because of the limited number of point ob- 
(a)
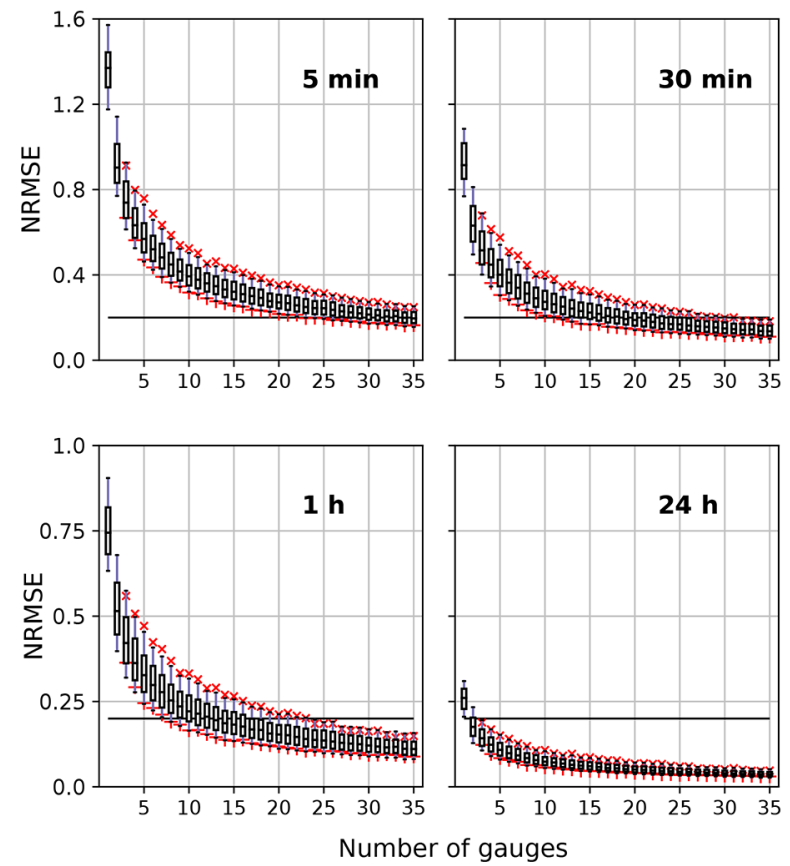

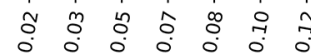

Gauge density [per $\mathrm{km}^{2}$ ] (b)
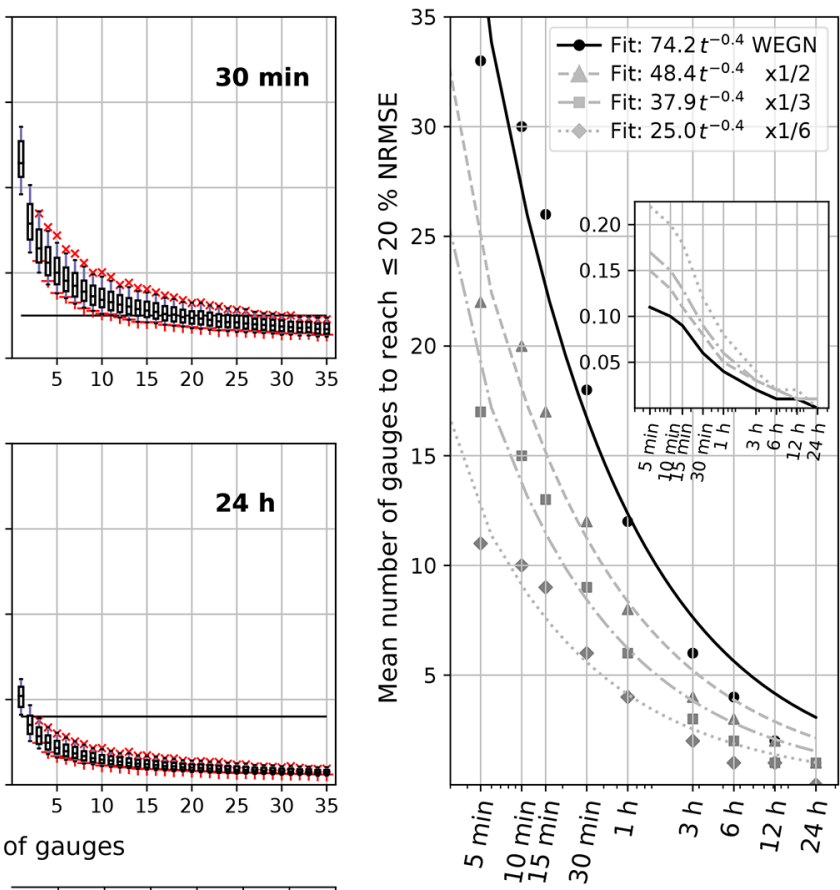

(c)

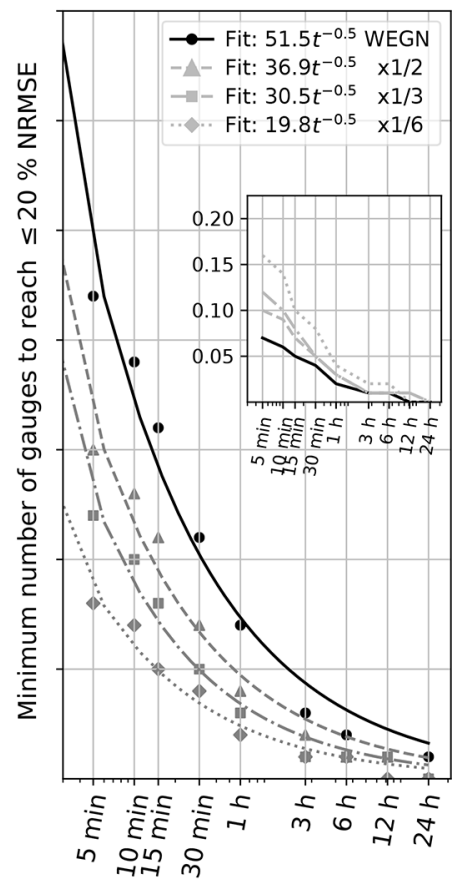

Figure 6. (a) Dependence of the accuracy of WEGN areal rainfall estimates on the number of gauges during heavy rainfall. Normalized RMSEs (NRMSEs) of 1000 random gauge combinations are used to assess the accuracy for each $n$-gauge network. Four selected time accumulations are shown. Black horizontal lines correspond to $20 \%$ NRMSE. Box plots display the median and 25th and 75 th percentiles of NRMSE distribution, and whiskers extend to the 10th and 90th percentiles. Red crosses and x symbols show the median NRMSE for good and bad gauge configurations; 100 cases are selected, respectively, for each of the 1000 combinations. (b) The average number of gauges required to obtain areal rainfall estimates with the NRMSE $<20 \%$ within the whole WEGN area (black) and within the WEGN $\times 1 / 2$, WEGN $\times 1 / 3$, and WEGN $\times 1 / 6$ areas (grey). Inset shows the results in terms of gauge density. (c) Same as (b) but for the minimum number of gauges required to obtain areal rainfall estimates with the NRMSE $<20 \%$. Note that (a) shows the results with respect to the whole WEGN area.
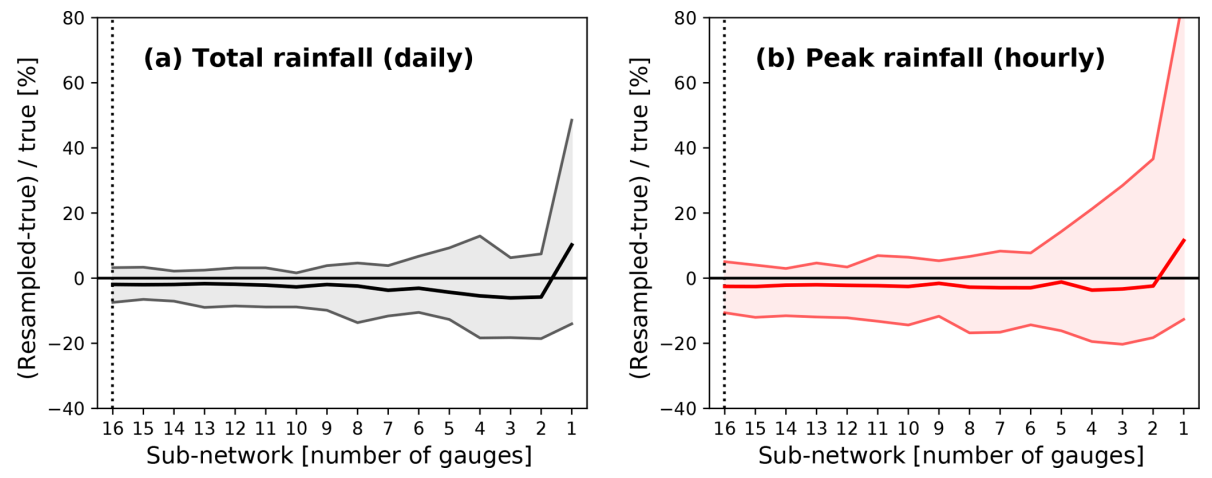

Figure 7. Dependence of the accuracy of (a) daily rainfall and (b) hourly peak intensity on the number of gauges. 71 heavy rain events are considered. The $y$ axis displays the relative difference between resampled and true rainfall. Resampled rainfall is calculated from $n$-gauge sub-networks, while true rainfall is calculated using the full density WEGN network. The thick lines show the median, and the shaded areas show the 10th to 90 th percentile spread. 


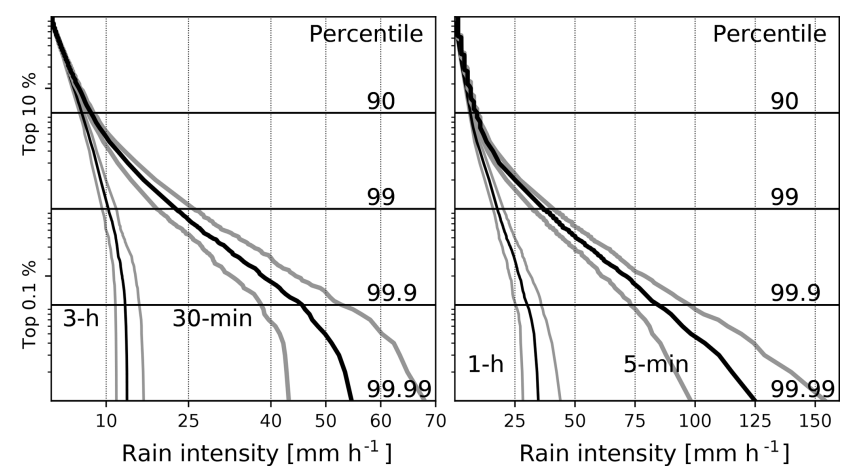

Figure 8. Distribution of gauge-level rainfall intensities corresponding to given percentile thresholds during heavy rainfall events. Four timescales are selected. Black lines show median values; grey lines show a 10th-90th percentile range among the gauges at a given threshold bin.

servations (Contractor et al., 2015; Hofstra et al., 2010; Peleg et al., 2018; Prein and Gobiet, 2017; Tozer et al., 2012). In addition to the high resolution, the regular distribution of WEGN gauges enables generating gridded rainfall fields that are homogeneous in space and, consequently, robustly assess uncertainty in rare and extreme rainfall represented in the data.

We generated gridded data using all 150 WEGN gauges and rescaled the data into horizontal resolutions from 0.01 to $0.1^{\circ}$ (hereafter HR01 to HR10). Spatial aggregation begins from the top-left corner towards the bottom right, and the remaining southern and/or eastern part of the grid is discarded (see Fig. 9). HR01 corresponds to about 1.1 and $0.8 \mathrm{~km}$ in latitudinal and longitudinal directions, respectively. The selected spatial scale affects statistics of extreme areal rainfall, such as daily extreme frequency. This is shown in Fig. 9, which illustrates the occurrence of days above a selected threshold: the top $5 \%$ of heavy rainfall events at HR01. The concept of the exceedance probability above thresholds is widely used in analyses of rainfall-triggered risk (e.g., Ban et al., 2015; Moberg et al., 2006; Schär et al., 2016). Some HR01-scale sites appear to experience extreme rainfall more frequency than other part of the region. In other words, highresolution data represent spatial variation and frequency of rainfall extremes well, neither of which is seen in lowerresolution data. Many existing gridded datasets are not likely to fully sample such site-level extreme events, owing to limited spatial resolution.

The exceedance probability of extreme rainfall across spatial resolutions is given in Fig. 10. The impact of different data resolutions on extreme rainfall occurrence is pronounced in both lower and upper tails. The highest daily rainfall during 10 years appears to be $68.4 \mathrm{~mm} \mathrm{~d}^{-1}$ at HR10 but $104.4 \mathrm{~mm} \mathrm{~d}^{-1}$ at HR01; the maximum record over the entire WEGN area is $64.1 \mathrm{~mm} \mathrm{~d}^{-1}$, so the ratio of the site-toareal extreme rainfall ranges from 1.07 to 1.63 depending on the considered spatial scale. We also demonstrate 99.9th and 99th percentiles of heavy rainfall intensities as a function of space and timescales. As shown in Fig. 11, the impact of spatial aggregation is more obvious at the sub-hourly scales. The 5 min extreme intensity increases from HR01 to HR 10 by $44 \%$ for the 99.9 th percentile, while it increases by $25 \%$ for the 99 th percentile. The $24 \mathrm{~h}$ extreme intensity increases by $33 \%$ and by $12 \%$ for the 99.9 th percentile and the 99th percentile, respectively. Note that temporal aggregation also significantly alters the definition of extremes.

\section{Summary and conclusions}

In this study, to quantify spatial variability in heavy rainfall and associated uncertainty, we used 10-year rainfall measurement data from the 150 rain gauges, uniformly spaced over the WEGN network in southeastern Austria. First, spatial correlation between the gauge records was examined. We found that the degree of spatial rainfall variability can be substantially different not only within years (warm versus cold seasons) but also between years. This implies that long-term data should be considered in obtaining comprehensive perspectives on regional rainfall variability. We found that during the cold season, the density of gauges is less of a concern (showing longer correlation distance) compared to the warm season. However, low values of the nugget effect parameter imply that snow or light rain measurements during winter time remain a challenge, especially at short timescales. Additionally, we found anisotropic patterns in the spatial correlations, indicating that the assumption of isotropic correlations can be another source of uncertainty (under certain weather conditions) in quantification of spatial variability in rainfall.

Secondly, we demonstrate how high density and regular distribution of WEGN gauges contribute to delivering accurate areal-precipitation estimation. The overall uncertainty in mean areal rainfall shows a clear dependence on the number of gauges and the temporal resolution considered for the estimation. To reach the same level of accuracy, the average number of gauges has to be increased roughly, following a power law as timescale decreases. Further analysis shows that there is no linear relation between the required number of gauges and the ratio of considered area size. The accuracy of areal rainfall estimation is also significantly dependent on the spatial configuration of the network. Additionally, we illustrate errors in the rainfall event statistics (e.g., total amount and peak hourly intensity of daily heavy rainfall events) due to an insufficient number of gauges. Our findings have implications concerning the use of sparse observational gauge data, for instance, in hydrologic modeling or rainfall estimate evaluation (e.g., Syed et al., 2003; Tian et al., 2018).

Lastly, using gridded WEGN data, rainfall extremes are reproduced at multiple spatial scales, approximately, from the grid resolution of regional to convective-permitting models (about 11.1 to $1.1 \mathrm{~km}$ in the latitudinal direction). We show 


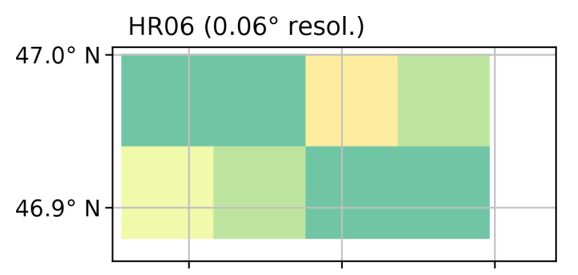

HR05 (0.05 resol.)
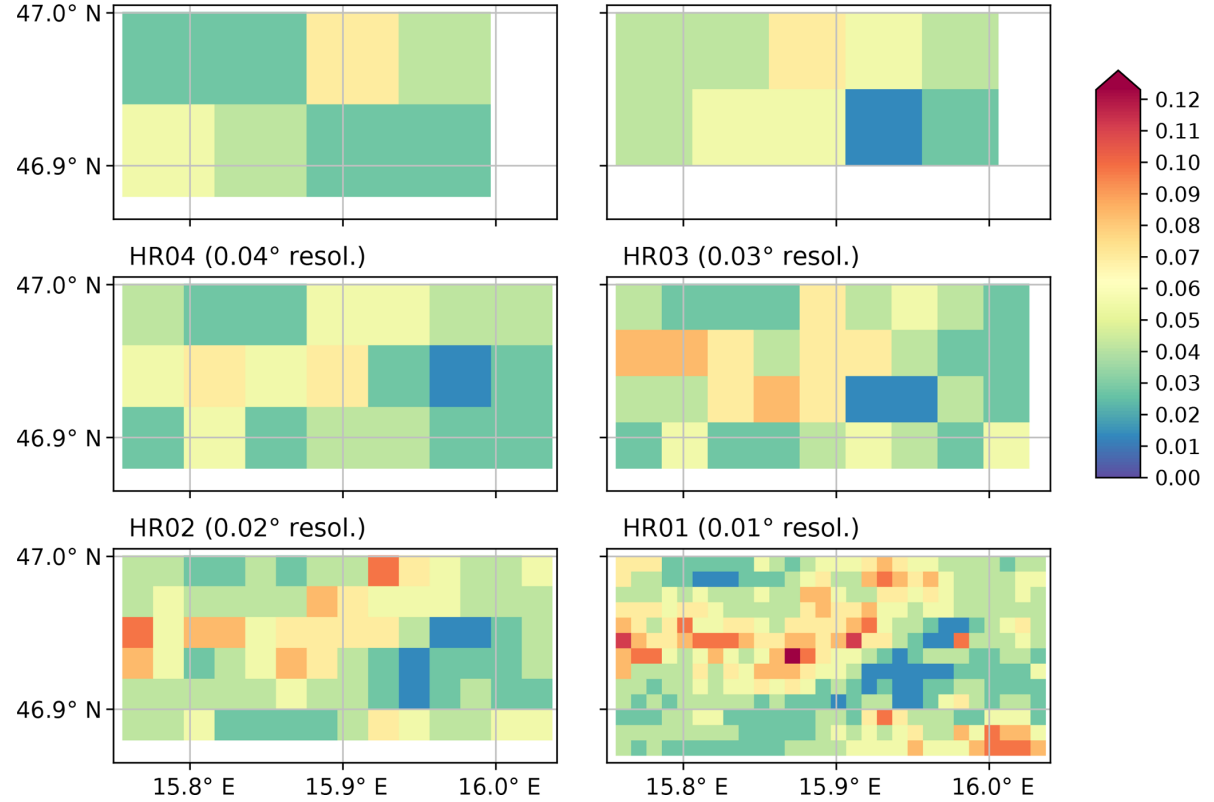

Figure 9. Occurrence of extreme events (defined as days with total rainfall $\geq 95$ th percentile of daily rainfall intensity during heavy rainfall events at HR01) at different horizontal grid spacings.

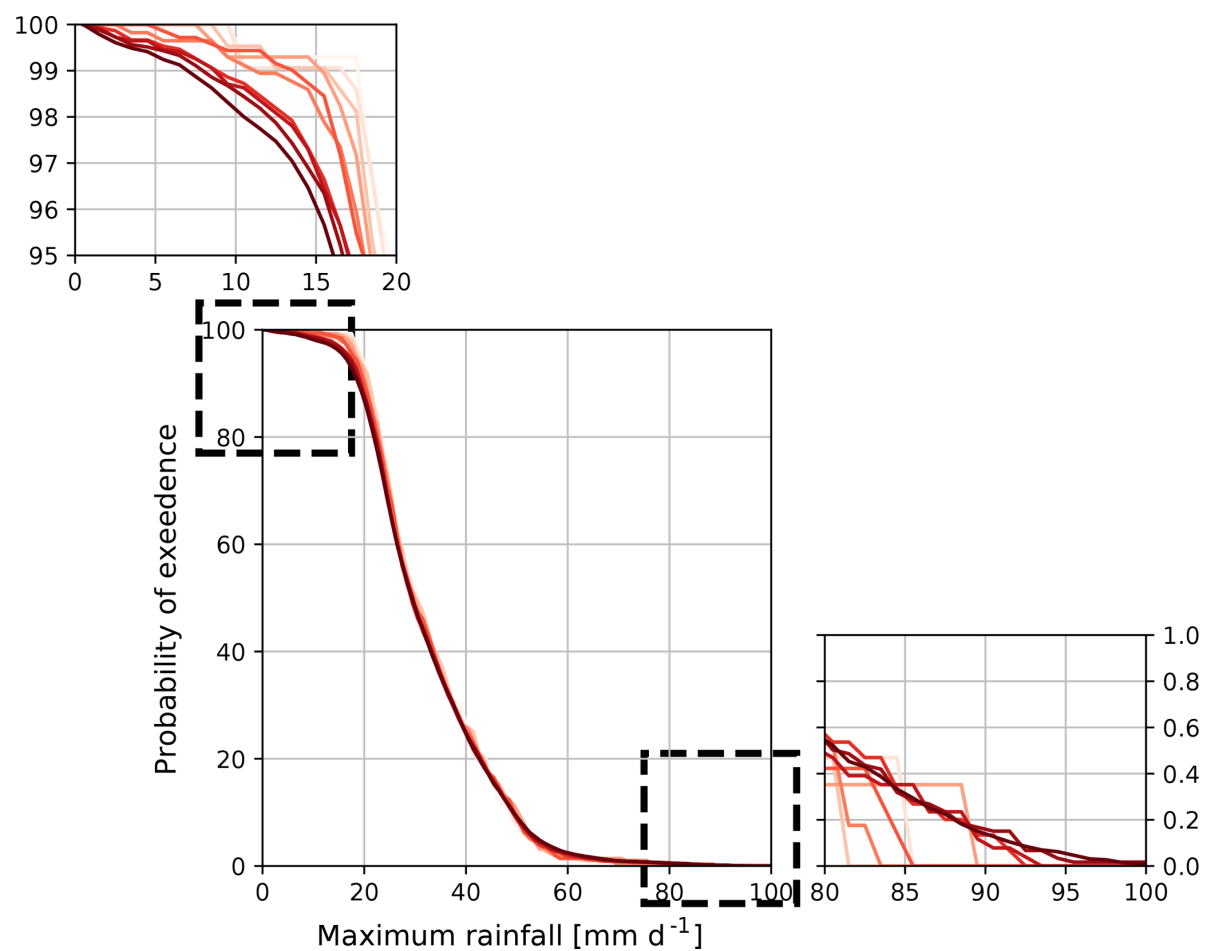

Figure 10. Probability of occurrence of heavy rainfall for different horizontal resolutions. Darker red represents higher horizontal resolution (from 0.1 to $0.01^{\circ}$ ). 

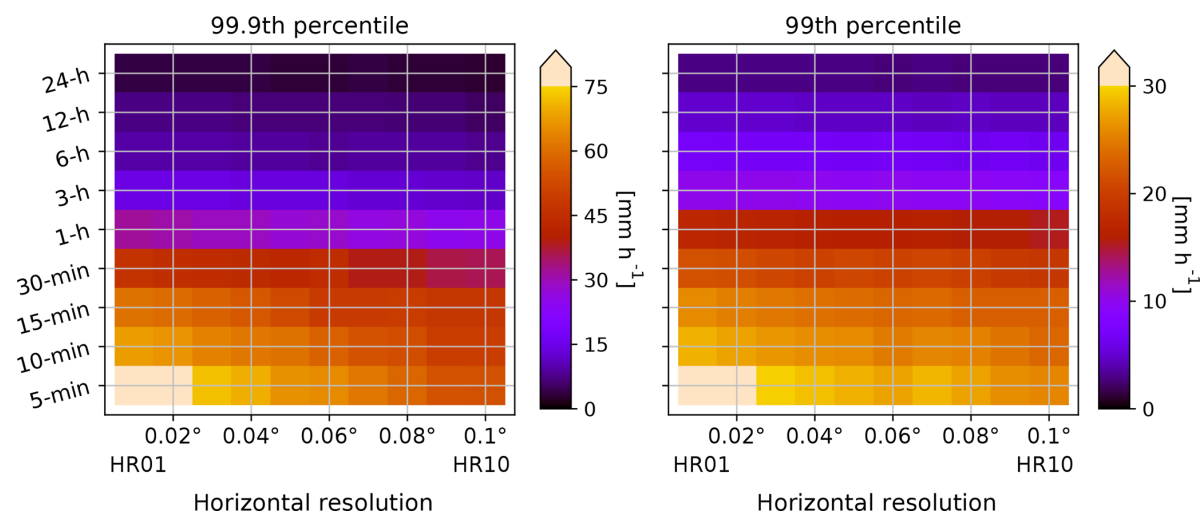

Figure 11. 99.9th and 99th percentiles of rainfall intensities derived from gridded rainfall fields with different spatial and temporal scales. Note the different color scale for the plots.

how different rainfall events can be considered extreme depending on the spatial and temporal resolutions. The results also demonstrate that high-resolution gridded data provide more reliable information not only in terms of the magnitude and frequency of extremes but also in terms of the exact location of the extremes. As a result, limited resolution of rainfall data can alter interpretations of rainfall statistics; extreme rainfall events at a location of interest $\left(a 0.01^{\circ} \times 0.01^{\circ}\right.$ site in our example) could occur more frequently and more intensely versus the local average. Localized information from high-resolution observation is the key for developing prevention and protection plans to mitigate potential damages of extreme rainfall in an efficient and adequate way. Our results highlight the need to evaluate uncertainty in extreme statistics derived from the existing datasets for supporting data selection among available rainfall data products.

In conclusion, the WEGN network provides a unique opportunity to empirically assess spatial variability in and uncertainty of surface rainfall directly based on gauge data. The network provides long-term records of more than a decade, which permits an exclusive focus on heavy rain events. Nonetheless, as stated in Villarini et al. (2008), there are only a few dense gauge networks on the catchment scale; therefore the verification of findings from studies in other regions is challenging. Regional factors, such as topography or rain type, can lead to differences in the degree of rainfall variability and uncertainty (e.g., Buytaert et al., 2006; Prein and Gobiet, 2017). Therefore, some of the general conclusions of this study may only be representative for midlatitude regions with moderate topography. In addition, more robust interpretation of the rainfall spatial structure beyond the network dimension $(>15 \mathrm{~km})$ needs to be complemented by additional larger-scale gauge data. For instance, Schroeer et al. (2018) used three different scales of networks, including the WEGN, to estimate the underestimation of maximum area precipitation of extreme convective over the range of 1 to $30 \mathrm{~km}$. It should be noted that WEGN has a high flexibility in terms of providing rainfall data within various spatial scales thanks to both high-resolution and quasi-grid configuration of the gauges. In this context, WEGN will continue providing observational evidence to explore rainfall processes at the local scale to the continental scale in the coming years.

Data availability. WegenerNet data products are available at https: //wegenernet.org/portal/ (last access: 3 July 2019).

Supplement. The supplement related to this article is available online at: https://doi.org/10.5194/hess-23-2863-2019-supplement.

Author contributions. Both authors set up and designed the study. SO performed the computational work and prepared the paper, with contributions by UF.

Competing interests. The authors declare that they have no conflict of interest.

Acknowledgements. The authors thank Gottfried Kirchengast and Jürgen Fuchsberger (University of Graz) for fruitful discussions. WegenerNet funding is provided by the Austrian Ministry for Science and Research, the University of Graz, the state of Styria (which also included European Union Regional Development funds), and the city of Graz; detailed information can be found at https: //wegcenter.uni-graz.at/de/wegenernet/wegenernet-home/ (last access: 3 July 2019)

Financial support. This research has been supported by the Austrian Science Fund (FWF) Doctoral Programme Climate Change Uncertainties, Thresholds and Coping Strategies (grant no. W 1256G15). 
Review statement. This paper was edited by Nadav Peleg and reviewed by two anonymous referees.

\section{References}

Ban, N., Schmidli, J., and Schär, C.: Heavy precipitation in a changing climate: Does short-term summer precipitation increase faster?, Geophys. Res. Lett., 42, 1165-1172, https://doi.org/10.1002/2014GL062588, 2015.

Bárdossy, A. and Das, T.: Influence of rainfall observation network on model calibration and application, Hydrol. Earth Syst. Sci., 12, 77-89, https://doi.org/10.5194/hess-12-77-2008, 2008.

Berezowski, T., Szcześniak, M., Kardel, I., Michałowski, R., Okruszko, T., Mezghani, A., and Piniewski, M.: CPLFDGDPT5: High-resolution gridded daily precipitation and temperature data set for two largest Polish river basins, Earth Syst. Sci. Data, 8, 127-139, https://doi.org/10.5194/essd-8-127-2016, 2016.

Buytaert, W., Celleri, R., Willems, P., Biévre, B. D., and Wyseure, G.: Spatial and temporal rainfall variability in mountainous areas: A case study from the south Ecuadorian Andes, J. Hydrol., 329, 413-421, https://doi.org/10.1016/j.jhydrol.2006.02.031, 2006.

Chaudhary, S., Dhanya, C., and Vinnarasi, R.: Dry and wet spell variability during monsoon in gauge-based gridded daily precipitation datasets over India, J. Hydrol., 546, 204-218, https://doi.org/10.1016/j.jhydrol.2017.01.023, 2017.

Ciach, G. J. and Krajewski, W. F.: On the estimation of radar rainfall error variance, Adv. Water Resour., 22, 585-595, https://doi.org/10.1016/S0309-1708(98)00043-8, 1999.

Ciach, G. J. and Krajewski, W. F.: Analysis and modeling of spatial correlation structure in small-scale rainfall in Central Oklahoma, Adv. Water Resour., 29, 1450-1463, https://doi.org/10.1016/j.advwatres.2005.11.003, 2006.

Contractor, S., Alexander, L. V., Donat, M. G., and Herold, N.: How well do gridded datasets of observed daily precipitation compare over Australia?, Adv. Meteorol., 2015, 325718, https://doi.org/10.1155/2015/325718, 2015.

Dai, A., Lin, X., and Hsu, K.-L.: The frequency, intensity, and diurnal cycle of precipitation in surface and satellite observations over low- and mid-latitudes, Clim. Dynam., 29, 727-744, https://doi.org/10.1007/s00382-007-0260-y, 2007.

Dhib, S., Mannaerts, C. M., Bargaoui, Z., Retsios, V., and Maathuis, B. H.: Evaluating the MSG satellite MultiSensor Precipitation Estimate for extreme rainfall monitoring over northern Tunisia, Weather Clim. Extrem., 16, 14-22, https://doi.org/10.1016/j.wace.2017.03.002, 2017.

Eggert, B., Berg, P., Haerter, J. O., Jacob, D., and Moseley, C.: Temporal and spatial scaling impacts on extreme precipitation, Atmos. Chem. Phys., 15, 5957-5971, https://doi.org/10.5194/acp15-5957-2015, 2015.

Gebremichael, M. and Krajewski, W. F.: Assessment of the statistical characterization of small-scale rainfall variability from radar: analysis of TRMM ground validation datasets, J. Appl. Meteorol. Clim., 43, 1180-1199, https://doi.org/10.1175/15200450(2004)043<1180:AOTSCO>2.0.CO;2, 2004.

Girons Lopez, M., Wennerström, H., Nordén, L.-Å., and Seibert, J.: Location and density of rain gauges for the estimation of spatial varying precipitation, Geogr. Ann. A, 97, 167-179, https://doi.org/10.1111/geoa.12094, 2015.

Habib, E. and Krajewski, W. F.: Uncertainty analysis of the TRMM ground-validation radar-rainfall products: Application to the TEFLUN-B field campaign, J. Appl. Meteorol. Clim., 41, 558-572, https://doi.org/10.1175/15200450(2002)041<0558:UAOTTG>2.0.CO;2, 2002.

Habib, E., Krajewski, W. F., and Ciach, G. J.: Estimation of rainfall interstation correlation, J. Hydrometeorol., 2, 621-629, https://doi.org/10.1175/15257541(2001)002<0621:EORIC>2.0.CO;2, 2001.

Hofstätter, M. and Blöschl, G.: Vb Cyclones Synchronized With the Arctic-/North Atlantic Oscillation, J. Geophys. Res.-Atmos., 124, 3259-3278, https://doi.org/10.1029/2018JD029420, 2019.

Hofstra, N., New, M., and McSweeney, C.: The influence of interpolation and station network density on the distributions and trends of climate variables in gridded daily data, Clim. Dynam., 35, 841-858, https://doi.org/10.1007/s00382-009-0698-1, 2010.

Hou, A. Y., Kakar, R. K., Neeck, S., Azarbarzin, A. A., Kummerow, C. D., Kojima, M., Oki, R., Nakamura, K., and Iguchi, T.: The Global Precipitation Measurement mission, B. Am. Meteorol. Soc., 95, 701-722, https://doi.org/10.1175/BAMS-D-1300164.1, 2014.

Huff, F. A. and Shipp, W. L.: Spatial correlations of storm, monthly and seasonal precipitation, J. Appl. Meteorol. Clim., 8, 542-550, https://doi.org/10.1175/15200450(1969)008<0542:SCOSMA>2.0.CO;2, 1969.

Hunter, J. D.: Matplotlib: A 2D graphics environment, Comput. Sci. Eng., 9, 90-95, https://doi.org/10.1109/MCSE.2007.55, 2007.

Jaffrain, J. and Berne, A.: Quantification of the small-scale spatial structure of the raindrop size distribution from a network of disdrometers, J. Appl. Meteorol. Clim., 51, 941-953, https://doi.org/10.1175/JAMC-D-11-0136.1, 2012.

Kann, A., Meirold-Mautner, I., Schmid, F., Kirchengast, G., Fuchsberger, J., Meyer, V., Tüchler, L., and Bica, B.: Evaluation of high-resolution precipitation analyses using a dense station network, Hydrol. Earth Syst. Sci., 19, 1547-1559, https://doi.org/10.5194/hess-19-1547-2015, 2015.

Keller, V. D. J., Tanguy, M., Prosdocimi, I., Terry, J. A., Hitt, O., Cole, S. J., Fry, M., Morris, D. G., and Dixon, H.: CEHGEAR: $1 \mathrm{~km}$ resolution daily and monthly areal rainfall estimates for the UK for hydrological and other applications, Earth Syst. Sci. Data, 7, 143-155, https://doi.org/10.5194/essd-7-1432015, 2015.

Kirchengast, G., Kabas, T., Leuprecht, A., Bichler, C., and Truhetz, H.: WegenerNet: A pioneering high-resolution network for monitoring weather and climate, B. Am. Meteorol. Soc., 95, 227-242, https://doi.org/10.1175/BAMS-D-11-00161.1, 2014.

Lockhoff, M., Zolina, O., Simmer, C., and Schulz, J.: Evaluation of satellite-retrieved extreme precipitation over Europe using gauge observations, J. Climate, 27, 607-623, https://doi.org/10.1175/JCLI-D-13-00194.1, 2014.

Ly, S., Charles, C., and Degré, A.: Geostatistical interpolation of daily rainfall at catchment scale: The use of several variogram models in the Ourthe and Ambleve catchments, Belgium, Hydrol. Earth Syst. Sci., 15, 2259-2274, https://doi.org/10.5194/hess-15-2259-2011, 2011.

Mandapaka, P. V. and Qin, X.: Analysis and characterization of probability distribution and small-scale spatial variability of rain- 
fall in Singapore using a dense gauge network, J. Appl. Meteorol. Clim., 52, 2781-2796, https://doi.org/10.1175/JAMC-D-130115.1, 2013.

Marra, F., Destro, E., Nikolopoulos, E. I., Zoccatelli, D., Creutin, J. D., Guzzetti, F., and Borga, M.: Impact of rainfall spatial aggregation on the identification of debris flow occurrence thresholds, Hydrol. Earth Syst. Sci., 21, 4525-4532, https://doi.org/10.5194/hess-21-4525-2017, 2017.

Matulla, C., Penlap, E. K., Haas, P., and Formayer, H.: Comparative analysis of spatial and seasonal variability: Austrian precipitation during the 20th century, Int. J. Climatol., 23, 1577-1588, https://doi.org/10.1002/joc.960, 2003.

Moberg, A., Jones, P. D., Lister, D., Walther, A., Brunet, M., Jacobeit, J., Alexander, L. V., Della-Marta, P. M., Luterbacher, J., Yiou, P., Chen, D., Klein Tank, A. M. G., Saladié, O., Sigró, J., Aguilar, E., Alexandersson, H., Almarza, C., Auer, I., Barriendos, M., Begert, M., Bergström, H., Böhm, R., Butler, C. J., Caesar, J., Drebs, A., Founda, D., Gerstengarbe, F.W., Micela, G., Maugeri, M., Österle, H., Pandzic, K., Petrakis, M., Srnec, L., Tolasz, R., Tuomenvirta, H., Werner, P. C., Linderholm, H., Philipp, A., Wanner, H., and Xoplaki, E.: Indices for daily temperature and precipitation extremes in Europe analyzed for the period 1901-2000, J. Geophys. Res., 111, D22106, https://doi.org/10.1029/2006JD007103, 2006.

O, S., Foelsche, U., Kirchengast, G., and Fuchsberger, J.: Validation and correction of rainfall data from the WegenerNet high density network in southeast Austria, J. Hydrol., 556, 1110-1122, https://doi.org/10.1016/j.jhydrol.2016.11.049, 2018a.

O, S., Foelsche, U., Kirchengast, G., Fuchsberger, J., Tan, J., and Petersen, W. A.: Evaluation of GPM IMERG Early, Late, and Final rainfall estimates using WegenerNet gauge data in southeastern Austria, Hydrol. Earth Syst. Sci., 21, 6559-6572, https://doi.org/10.5194/hess-21-6559-2017, 2018b.

Peleg, N., Ben-Asher, M., and Morin, E.: Radar subpixel-scale rainfall variability and uncertainty: Lessons learned from observations of a dense rain-gauge network, Hydrol. Earth Syst. Sci., 17, 2195-2208, https://doi.org/10.5194/hess-17-2195-2013, 2013.

Peleg, N., Marra, F., Fatichi, S., Paschalis, A., Molnar, P., and Burlando, P.: Spatial variability of extreme rainfall at radar subpixel scale, J. Hydrol., 556, 922-933, https://doi.org/10.1016/j.jhydrol.2016.05.033, 2018.

Prein, A. F. and Gobiet, A.: Impacts of uncertainties in European gridded precipitation observations on regional climate analysis: Uncertainty in European Precipitation, Int. J. Climatol., 37, 305327, https://doi.org/10.1002/joc.4706, 2017.

Schär, C., Ban, N., Fischer, E. M., Rajczak, J., Schmidli, J., Frei, C., Giorgi, F., Karl, T. R., Kendon, E. J., Tank, A. M. G. K., O'Gorman, P. A., Sillmann, J., Zhang, X., and Zwiers, F. W.: Percentile indices for assessing changes in heavy precipitation events, Climatic Change, 137, 201-216, https://doi.org/10.1007/s10584-016-1669-2, 2016.

Schroeer, K., Kirchengast, G., and O, S.: Strong dependence of extreme convective precipitation intensities on gauge network density, Geophys. Res. Lett., 45, 8253-8263, https://doi.org/10.1029/2018GL077994, 2018.

Sillmann, J., Thorarinsdottir, T., Keenlyside, N., Schaller, N., Alexander, L. V., Hegerl, G., Seneviratne, S. I., Vautard, R., Zhang, X., and Zwiers, F. W.: Understanding, modeling and predicting weather and climate extremes: Chal- lenges and opportunities, Weather. Clim. Soc., 18, 65-74, https://doi.org/10.1016/j.wace.2017.10.003, 2017.

Steiner, M., Smith, J. A., Burges, S. J., Alonso, C. V., and Darden, R. W.: Effect of bias adjustment and rain gauge data quality control on radar rainfall estimation, Water Resour. Res., 35, 2487-2503, https://doi.org/10.1029/1999WR900142, 1999.

Svensson, C. and Jones, D.: Review of methods for deriving areal reduction factors: Review of ARF methods, J. Flood Risk Manage., 3, 232-245, https://doi.org/10.1111/j.1753318X.2010.01075.x, 2010.

Svoboda, V., Máca, P., Hanel, M., and Pech, P.: Spatial correlation structure of monthly rainfall at a mesoscale region of north-eastern Bohemia, Theor. Appl. Climatol., 121, 359-375, https://doi.org/10.1007/s00704-014-1241-9, 2015.

Syed, K. H., Goodrich, D. C., Myers, D. E., and Sorooshian, S.: Spatial characteristics of thunderstorm rainfall fields and their relation to runoff, J. Hydrol., 271, 1-21, https://doi.org/10.1016/S0022-1694(02)00311-6, 2003.

Tan, J., Petersen, W. A., Kirchengast, G., Goodrich, D. C., and Wolff, D. B.: Evaluation of Gobal Precipitation Measurement rainfall estimates against three dense gauge networks, J. Hydrometeorol., 19, 517-532, https://doi.org/10.1175/JHM-D-170174.1, 2018.

Tian, F., Hou, S., Yang, L., Hu, H., and Hou, A.: How does the evaluation of the GPM IMERG rainfall product depend on gauge density and rainfall intensity?, J. Hydrometeorol., 19, 339-349, https://doi.org/10.1175/JHM-D-17-0161.1, 2018.

Tokay, A., Roche, R. J., and Bashor, P. G.: An experimental study of spatial variability of rainfall, J. Hydrometeorol., 15, 801-812, https://doi.org/10.1175/JHM-D-13-031.1, 2014.

Tozer, C. R., Kiem, A. S., and Verdon-Kidd, D. C.: On the uncertainties associated with using gridded rainfall data as a proxy for observed, Hydrol. Earth Syst. Sci., 16, 1481-1499, https://doi.org/10.5194/hess-16-1481-2012, 2012.

Velasco-Forero, C. A., Sempere-Torres, D., Cassiraga, E. F., and Jaime Gómez-Hernández, J.: A non-parametric automatic blending methodology to estimate rainfall fields from rain gauge and radar data, Adv. Water Resour., 32, 986-1002, https://doi.org/10.1016/j.advwatres.2008.10.004, 2009.

Villarini, G., Mandapaka, P. V., Krajewski, W. F., and Moore, R. J.: Rainfall and sampling uncertainties: A rain gauge perspective, J. Geophys. Res., 13, D11102, https://doi.org/10.1029/2007JD009214, 2008

Wood, S. J., Jones, D. A., and Moore, R. J.: Accuracy of rainfall measurement for scales of hydrological interest, Hydrol. Earth Syst. Sci., 4, 531-543, https://doi.org/10.5194/hess-4-531-2000, 2000.

Xu, H., Xu, C.-Y., Chen, H., Zhang, Z., and Li, L.: Assessing the influence of rain gauge density and distribution on hydrological model performance in a humid region of China, J. Hydrol., 505, 1-12, https://doi.org/10.1016/j.jhydrol.2013.09.004, 2013.

Yatagai, A., Kamiguchi, K., Arakawa, O., Hamada, A., Yasutomi, N., and Kitoh, A.: APHRODITE: Constructing a long-term daily gridded precipitation dataset for Asia based on a dense network of rain gauges, B. Am. Meteorol. Soc., 93, 1401-1415, https://doi.org/10.1175/BAMS-D-11-00122.1, 2012. 